\title{
ONE DIMENSIONAL WEIGHTED HARDY'S INEQUALITIES AND APPLICATION
}

\section{XiAojing LiU, Toshio Horiuchi, Hiroshi Ando}

\begin{abstract}
Let $\Omega$ be a $C^{2}$ class bounded domain of $\mathbb{R}^{n}(n \geqslant 1)$. In the present paper we shall improve one dimensional weighted Hardy inequalities with one-sided boundary condition by adding sharp remainders. As an application, we shall establish $n$ dimensional weighted Hardy inequalities with weight functions being powers of the distance function $\delta(x)$ to the boundary $\partial \Omega$. Our results will be applicable to variational problems in a coming paper [3].
\end{abstract}

Mathematics subject classification (2010): Primary 35J70; Secondary 35J60, 34L30, 26 D10. weights.

Keywords and phrases: Weighted Hardy's inequalities, weak Hardy property, $p$-Laplace operator with

\section{REFERENCES}

[1] Adimurthi, N. Nirmalendu, M. Chaudhuri and Mythily Ramaswamy, An improved Hardy-Sobolev inequality and its application, Proceedings of the American Mathematical Society, Vol. 130, No. 2, 2001, pp. 489-505.

[2] H. Ando, T. Horiuchi, Missing terms in the weighted Hardy-Sobolev inequalities and its application, Kyoto Journal of Mathematics, Vol. 52, No. 4, (2012), pp. 759-796.

[3] H. Ando, T. HoRIUCHI, Weighted Hardy's inequalities and the variational problem with compact perturbations, Mathematical Journal of Ibaraki University, Vol. 52, (2020), pp. 15-26.

[4] H. ANDO, T. HORIUCHI, E. NAKAI, Weighted Hardy inequalities with infinitely many sharp missing terms, Mathematical Journal of Ibaraki University, Vol. 46, (2014), pp. 9-30.

[5] H. Brezis, M. MARCus, Hardy's inequakities revisited, Annali della Scuola Normale Superiore di Pisa, Classe di Scienze $4^{e}$ série, tome 25, No. 1-2 (1997), pp. 217-237.

[6] E. B. Davies, The Hardy constant, Quart. J. math. Oxford (2), Vol. 46, (1995) pp. 417-431.

[7] A. Detalla, T. Horiuchi, H. Ando, Missing terms in Hardy-Sobolev inequalities, Proceedings of the Japan Academy, Vol. 80, Ser. A, No. 8, 2004, pp. 160-165.

[8] A. Detalla, T. Horiuchi, H. Ando, Missing terms in Hardy-Sobolev inequalities and its application, Far East Journal of Mathematical Sciences, Vol. 14, No. 3, 2004, pp. 333-359.

[9] A. Detalla, T. Horiuchi, H. Ando, Sharp remainder terms of Hardy-Sobolev inequalities, Mathematical Journal of Ibaraki University, Vol. 37 (2005), pp. 39-52.

[10] T. HORIUCHI, Hardy's Inequalities with non-doubling weights and sharp remainders, in preparation.

[11] A. KUfNer AND B. OpIC, Hardy-type inequalities, Pitman Research notes in mathematics series, Vol. 219, [London, Longman Group UK Limited, 1990].

[12] M. Marcus, V. J. Mizel, Y. Pinchover, On the best constant for Hardy's inequality in $\mathbf{R}^{\mathbf{n}}$, Transactions of the American Mathematical Society, Vol. 350, No. 8, August (1998), pp. 3237-3255.

[13] T. MatsKewich And P. E. SobolevsKiI, The best possible constant in a generalized Hardy's inequality for convex domains in $\mathbf{R}^{\mathbf{n}}$, Nonlinear Analysis, Vol. 28, (1997) pp. 1601-1610.

[14] V. G. MAZ'JA, Sobolev spaces (2nd edition), Springer, 2011.

[15] Y. Shen, Z. Chen, Sharp Hardy-Sobolev inequalities with general weights and remainder terms, Journal of inequalities and applications, Volume 2009, Article ID 419845, 24 pages, doi:10.1155/2009/419845. 